\title{
Endoscopic management of obstructive pancreatitis with a metal stent in two family members with hereditary cationic trypsinogen (PRSS1) deficiency
}
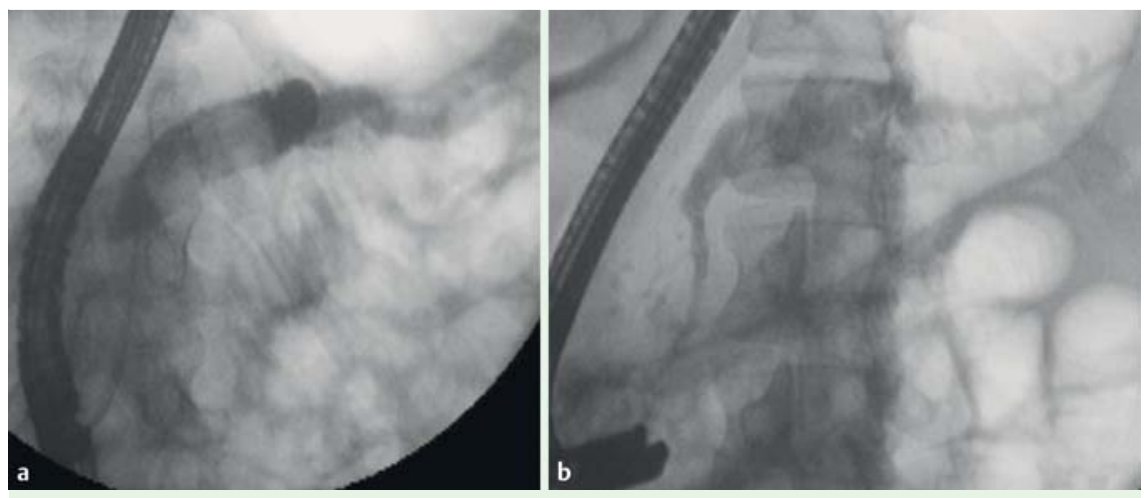

Fig. 1 Fluoroscopic view of the pancreatic duct of a 37-year-old woman with genetically proven hereditary cationic trypsinogen (PRSS1) deficiency pancreatitis: a before endoscopic treatment; $\mathbf{b}$ after endoscopic treatment.
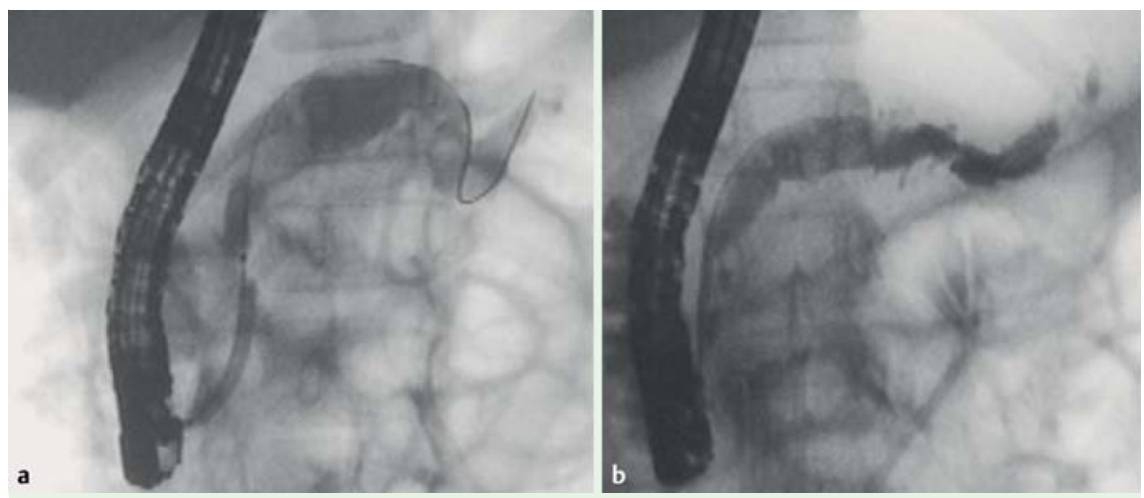

Fig. 2 Fluoroscopic view of the pancreatic duct of the 12-year-old daughter of the patient of $\bullet$ Fig. 1: a before endoscopic treatment; $\mathbf{b}$ during endoscopic treatment.

We report here the case of a 37-year-old woman and her daughter (now 12 years old) with genetically proven hereditary cationic trypsinogen (PRSS1) deficiency pancreatitis. The two patients were treated in a similar manner: endoscopic extraction of large obstructive stones located mainly in the head of the pancreas upstream of a stricture of the distal (cephalic) pancreatic duct and associated with extreme dilation $(10-15 \mathrm{~mm})$ of the pancreatic duct, manifesting as bouts of mild acute pancreatitis and abdominal pain that could not relieved with analgesics (० Fig. 1-3).

Both patients underwent pancreatic sphincterotomy, hydrostatic dilation of the pancreatic duct stricture with a $6-\mathrm{mm}$ Hurricane RX Biliary Dilation Balloon (Boston Scientific, Natick, Massachusetts, USA), removal of the stone fragments with a Dormia basket, and placement of an 8-mm-diameter, 60-mm-long fully covered self-expandable metal stent (SEMS) (WallFlex Biliary RX Stent; Boston Scientific) to dilate the stricture and facilitate removal of the remaining stone fragments ( $\bullet$ Fig.4 and $\bullet$ Fig.5). The mother's stent was left in place for 1 month and the daughter's for 2 weeks.

After stent removal, the mother experienced one episode of abdominal pain, with no further symptomatic relapse so far. Because of two flares of recurrent mild pancreatitis, the daughter underwent additional endoscopic therapeutic sessions; these consisted of a second stricture dilation, followed by placement of another fully covered SEMS for 3 months (same device) and subsequent placement of a 10-Fr plastic stent (Johlin Stent; Cook Medical, Winston-Salem, North Carolina, USA), which was withdrawn 3 months later. Since this procedure, the daughter has remained asymptomatic and has resumed school attendance uneventfully.

Optimal stenting modalities have not been detailed in the rare reports devoted to patients with this condition [1 $1-5]$. The use of fully covered SEMS was of particular interest in these two patients, who presented with similar findings (short distal stricture and unusually large upstream dilation), because these stents can facilitate the removal of large stones and reduce the discrepancy between duct size in the head and body of the pancreas, a major factor in stone formation.

Endoscopy_UCTN_Code_TTT_1AR_2AH

Competing interests: None

Marine Camus ${ }^{1,2}$, Sarah Leblanc ${ }^{1}$, Dominique Debray ${ }^{2,3}$, Ulriikka Chaput ${ }^{4}$, Stanislas Chaussade ${ }^{1,2}$, Frédéric Prat ${ }^{1,2}$

${ }^{1}$ Department of Gastroenterology, Cochin Hospital, APHP, Paris, France

${ }^{2}$ Faculté Paris Descartes, Paris, France

${ }^{3}$ Pediatric Hepatology, Necker Hospital, APHP, Paris, France

${ }^{4}$ Department of Hepatogastroenterology, Lariboisière Hospital, APHP, Paris, France

\section{References}

1 Ceppa EP, Pitt HA, Hunter JL et al. Hereditary pancreatitis: endoscopic and surgical management. J Gastrointest Surg 2013; 17: $847-856$

2 Choudari CP, Nickl NJ, Fogel E et al. Hereditary pancreatitis: clinical presentation, ERCP findings, and outcome of endoscopic therapy. Gastrointest Endosc 2002; 56: 66 71

3 Patel MR, Eppolito AL, Willingham FF. Hereditary pancreatitis for the endoscopist. Therap Adv Gastroenterol 2013; 6: 169-179

4 Dever JB, Irani S, Brandabur J et al. Outcomes of interventional ERCP in hereditary pancreatitis. J Clin Gastroenterol 2010; 44: 46 51

5 Vaughan D, Imrie C, Kelleher J et al. Pancreatic duct stenting as a treatment for hereditary pancreatitis. Pediatrics 1999; 104 : $1129-1133$ 

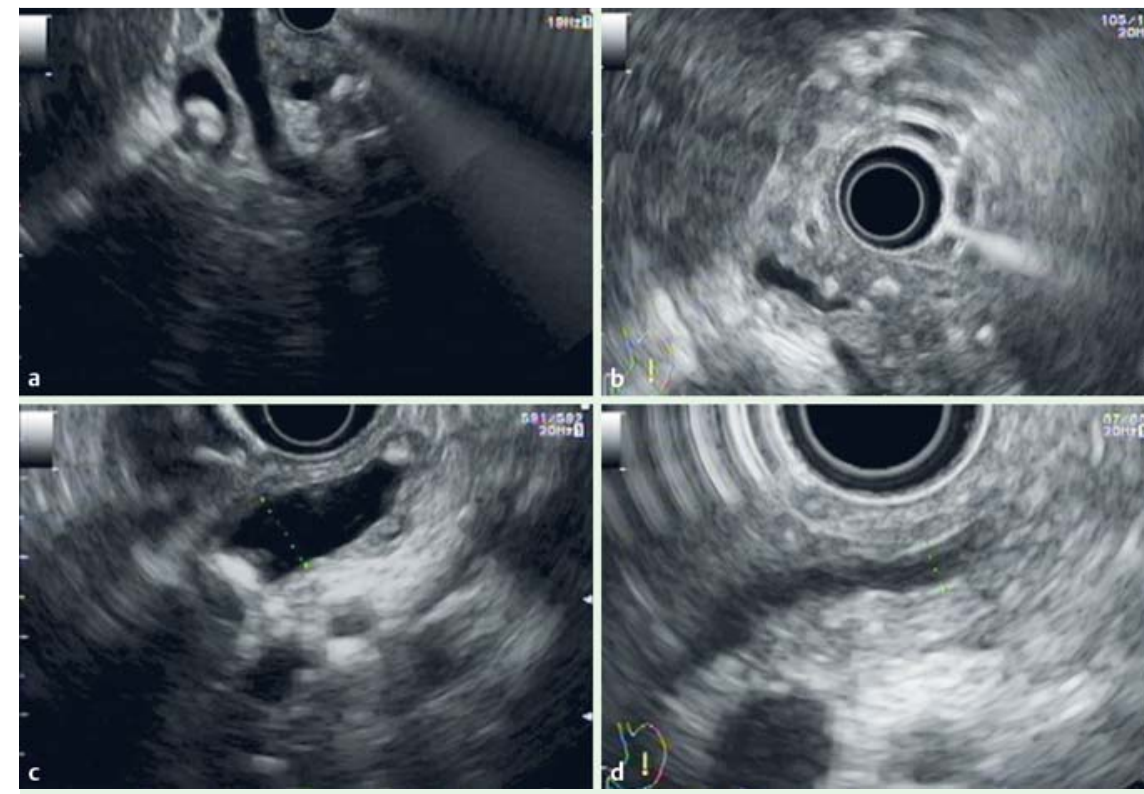

Fig. 3 Endoscopic ultrasound views of the patient in $\bullet$ Fig. 2 (the daughter): a, b stones in the dilated pancreatic duct; $\mathbf{c}$ after treatment, stones in the pancreatic parenchyma (whereas the main pancreatic duct is free of stones); $\mathbf{d}$ the pancreatic duct after treatment, exhibiting a moderately enlarged caliber.

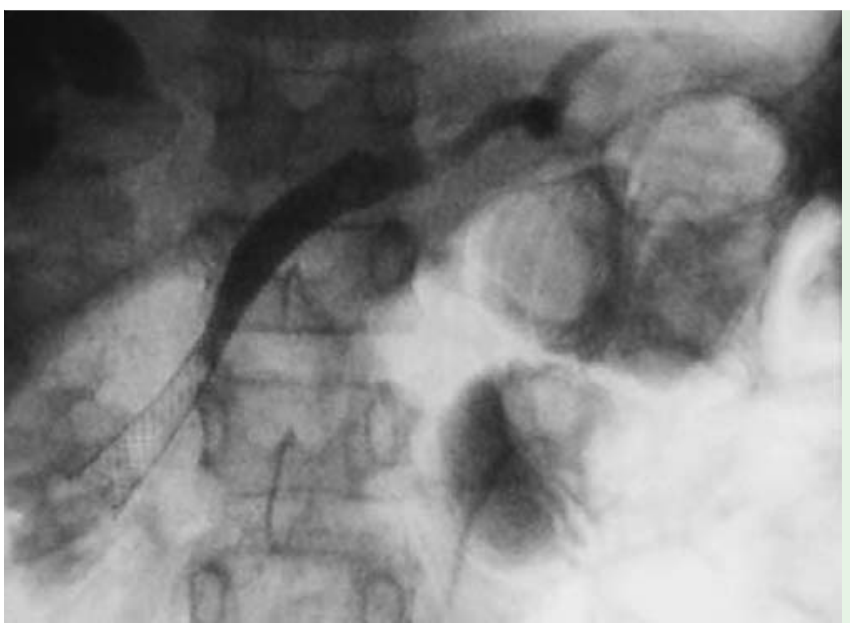

Fig. 4 Fully covered self-expandable metal stent in the pancreatic duct.

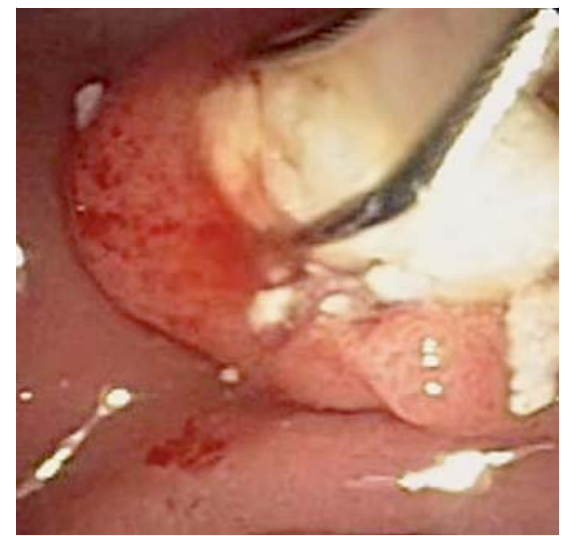

Fig. 5 Duodenoscopic view of the removal of stone fragments with the Dormia basket.

\section{Bibliography}

DOI http://dx.doi.org/

10.1055/s-0034-1392428

Endoscopy 2015; 47: E383-E384

(c) Georg Thieme Verlag KG

Stuttgart · New York

ISSN 0013-726X

\section{Corresponding author}

Marine Camus, MD

Department of Gastroenterology

Cochin Hospital

27 rue du Faubourg Saint-Jacques 75014 Paris

France

Fax: +33-1-58-41-19-65

marine.camus@cch.aphp.fr 